\title{
Study on the Relationship Between Fractal Dimension of Particle Size Distribution and Mechanical Properties of Portland Cement
}

\author{
Jun Liu ${ }^{1,2, a}$, Jiao Ge ${ }^{1, b}$ \\ ${ }^{1}$ School of Materials Science and Engineering, Shenyang Jianzhu University, Shenyang, China \\ ${ }^{2}$ School of Materials Science and Engineering, Shenyang Ligong University, Shenyang, China \\ âEmail:liujun2699@126.com, ${ }^{\mathrm{b}}$ Email:2865373720@qq.com
}

Keywords: Fly ash; Particle size distribution; Fractal dimension model; Strength of the mortar.

Abstract. Particle size distribution of fly ash conforming to variable distribution functions were obtained. Fractal dimension of the fly ash were calculated and mechanical properties of the resulting mortar were studied. The results show that the fractal dimension of fly ash with varied particle size distributions ranges from 2.03573 to 2.66567 (except the normal distribution $(\mu=12.5)$ that with a fractal dimension of 1.27745). It shows that the particle size distribution of fly ash has good fractal characteristics and the fractal dimension of the fly ash has a good correlation with the flexural and compressive strength of mortar.

\section{Introduction}

The activity of fly ash[1-3] is quite different due to the difference between the original chemical composition and the combustion process. Commonly, ultra-fine grinding technology and chemical excitation were used to improve its activity at present. However, the influence of particle size distribution on the mechanical properties of mortar is seldom considered. Therefore, using the most typical S.Tsivilis distribution and Andersen distribution, and the most commonly used normal distribution in engineering mathematics to establish the particle size gradation of fly ash.In this paper, the fractal dimension estimation model of particle size distribution of cement particles is applied; fly ash was calculated S.Tsivilis distribution, Andersen distribution and normal distribution of fractal dimension. Further study in the chemical composition and mineral composition of the same basic conditions. The relationship between the fractal dimension of particle size distribution of fly ash and the mechanical properties of cement mortar. In the actual production, we try to use the fractal dimension of the particle size distribution of fly ash as a qualitative parameter of the mechanical properties of cement mortar.

\section{Experimental}

Raw materials. Cement: 42.5 ordinary Portland cement, the chemical composition is shown in Table 1 . Fly ash: Grade II, the chemical composition shown in Table 1. Sand: Clean the sand without sludge after cleaning. Mixing water: tap water. Water reducing agent: naphthalene superplasticizer, the water reduction rate of $20 \%$.

Table 1 Chemical composition of cement and fly ash (\%)

\begin{tabular}{ccccccccc}
\hline Materials & $\mathrm{SiO}_{2}$ & $\mathrm{Al}_{2} \mathrm{O}_{3}$ & $\mathrm{CaO}$ & $\mathrm{MgO}$ & $\mathrm{Fe}_{2} \mathrm{O}_{3}$ & $\mathrm{~K}_{2} \mathrm{O}$ & $\mathrm{Na}_{2} \mathrm{O}$ & $\mathrm{R}_{2} \mathrm{O}$ \\
\hline Cement & 21.72 & 5.81 & 62.41 & 1.73 & 4.33 & --- & --- & 0.50 \\
Fly ash & 59.95 & 26.78 & 4.35 & 2.30 & 1.53 & 1.25 & 2.75 & --- \\
\hline
\end{tabular}

Test process. Fly ash is sieved through the standard sieves, and 12 different particle sizes of fly ash was obtained, then the content of the associated interval was further adjusted until it satisfies S.Tsivilis distribution, Andersen distribution and Normal distribution. The quality of each particle size interval is shown in Table 2. The fly ash-Portland cement was mixed with sand in accordance with GB/T17671-1999 "cement mortar strength test method" to prepare mortar (Sand ratio of 1:3; 
Water-cement ratio of 0.42 , the water reducing agent is $1.2 \%$ ). The resulting mortars were curing under standard condition to the specified age $(3 \mathrm{~d}, 7 \mathrm{~d}, 14 \mathrm{~d})$ before compression strength and flexural strength tests.

Table 2 The mass fraction percentage of the fly ash with variable particle size intervals conforming to the S.Tsivilis distribution, Andersen distribution and Normal distribution (\%)

\begin{tabular}{|c|c|c|c|c|c|c|c|c|c|c|c|c|c|}
\hline \multirow[b]{2}{*}{ Distribution } & \multicolumn{13}{|c|}{ Particle size interval $(\mu \mathrm{m})$} \\
\hline & $\begin{array}{c}0 \sim \\
3\end{array}$ & $\begin{array}{c}3 \sim \\
5\end{array}$ & $\begin{array}{c}5 \sim \\
8\end{array}$ & $\begin{array}{l}8 \sim \\
10\end{array}$ & $\begin{array}{c}10 \\
\sim \\
15\end{array}$ & $\begin{array}{c}15 \\
\sim \\
20\end{array}$ & $\begin{array}{c}20 \\
\sim \\
26\end{array}$ & $\begin{array}{c}26 \\
\sim \\
30 . \\
8\end{array}$ & $\begin{array}{c}30 . \\
8 \sim \\
38 . \\
5\end{array}$ & $\begin{array}{l}38 . \\
5 \sim \\
43\end{array}$ & $\begin{array}{c}43 \\
\sim \\
50\end{array}$ & $\begin{array}{c}50 \\
\sim \\
61\end{array}$ & $\begin{array}{c}61 \\
\sim \\
80\end{array}$ \\
\hline $\begin{array}{c}\text { S.Tsivilis } \\
\text { distribution(1) }\end{array}$ & $\begin{array}{c}5.0 \\
0\end{array}$ & \multicolumn{7}{|c|}{82.500} & \multicolumn{5}{|c|}{12.50} \\
\hline $\begin{array}{c}\text { S.Tsivilis } \\
\text { distribution(2) }\end{array}$ & $\begin{array}{l}10 . \\
00\end{array}$ & \multicolumn{7}{|c|}{65.00} & \multicolumn{5}{|c|}{25.00} \\
\hline $\begin{array}{c}\text { Andersen distribution } \\
(n=1 / 3)\end{array}$ & $\begin{array}{l}33 . \\
47\end{array}$ & $\begin{array}{c}6.2 \\
2\end{array}$ & $\begin{array}{c}6.7 \\
3\end{array}$ & $\begin{array}{c}3.2 \\
8\end{array}$ & $\begin{array}{c}7.2 \\
4\end{array}$ & $\begin{array}{c}5.7 \\
6\end{array}$ & $\begin{array}{c}5.7 \\
5\end{array}$ & $\begin{array}{c}4.0 \\
0\end{array}$ & $\begin{array}{c}5.2 \\
6\end{array}$ & $\begin{array}{c}2.9 \\
4\end{array}$ & $\begin{array}{c}4.1 \\
9\end{array}$ & $\begin{array}{c}5.8 \\
6\end{array}$ & $\begin{array}{c}8.6 \\
4\end{array}$ \\
\hline $\begin{array}{l}\text { Andersen distribution } \\
(n=0.37)\end{array}$ & $\begin{array}{c}0.0 \\
0\end{array}$ & $\begin{array}{c}807 \\
8\end{array}$ & $\begin{array}{c}906 \\
7\end{array}$ & $\begin{array}{c}5.2 \\
2\end{array}$ & $\begin{array}{l}10 . \\
66\end{array}$ & $\begin{array}{c}8.5 \\
9\end{array}$ & $\begin{array}{c}8.6 \\
8\end{array}$ & $\begin{array}{c}6.0 \\
7\end{array}$ & $\begin{array}{c}8.5 \\
9\end{array}$ & $\begin{array}{c}4.5 \\
2\end{array}$ & $\begin{array}{c}6.4 \\
9\end{array}$ & $\begin{array}{c}9.1 \\
2\end{array}$ & $\begin{array}{l}13 . \\
61\end{array}$ \\
\hline $\begin{array}{l}\text { Normal distribution } \\
\qquad(\mu=6.5)\end{array}$ & $\begin{array}{l}16 . \\
08\end{array}$ & $\begin{array}{l}15 . \\
51\end{array}$ & $\begin{array}{r}26 . \\
10\end{array}$ & $\begin{array}{l}15 . \\
51\end{array}$ & $\begin{array}{l}21 . \\
87\end{array}$ & $\begin{array}{c}4.5 \\
6\end{array}$ & $\begin{array}{c}0.3 \\
7\end{array}$ & \multicolumn{6}{|c|}{0.00} \\
\hline $\begin{array}{l}\text { Normal distribution } \\
\qquad(\mu=12.5)\end{array}$ & $\begin{array}{c}2.2 \\
7\end{array}$ & $\begin{array}{c}3.8 \\
4\end{array}$ & $\begin{array}{l}11 . \\
80\end{array}$ & $\begin{array}{l}12 . \\
52\end{array}$ & $\begin{array}{c}38 . \\
50\end{array}$ & $\begin{array}{l}24 . \\
32\end{array}$ & $\begin{array}{c}6.3 \\
9\end{array}$ & $\begin{array}{c}0.3 \\
6\end{array}$ & \multicolumn{5}{|c|}{0.00} \\
\hline
\end{tabular}

\section{Results and discussions}

Dimensional measurement model. Calculation model of fractal dimension of particle size distribution [4-6]

$$
m\left(\delta<d_{i}\right) / m_{0}=\left(d_{i} / D\right)^{3-D_{1}}
$$

Where: $\delta$ is the gauge for measuring fly ash; $d_{i}$ is the size of each grade of fly ash; $D$ is the size of the largest particles of fly ash when screening; $D_{1}$ is the fractal dimension of the particle size distribution of fly ash; $m\left(\delta<d_{i}\right)$ is the total mass of fly ash particles with particle size less than or equal to $d_{i} ; m_{0}$ is the total mass of all fly ash particles.

And then both sides of the type (1) was conducted a logarithm for constant deformation, then:

$$
\lg \left[m\left(\delta<d_{i}\right) / m_{0}\right]=\left(3-D_{1}\right) \lg \left(d_{i} / D\right)
$$

$\lg \left(d_{i} / D\right)$ and $\lg \left[m\left(\delta<d_{i}\right) / m_{0}\right]$ are horizontal and vertical coordinate. In the double logarithmic coordinate system mapping, the fitting curve is obtained as follows:

$$
Y=A+B \cdot X
$$

Then

$$
D_{1}=3-B
$$

Using the formula (2) and (4) to fit the data in Table 1, the fractal dimension of particle size distribution of fly ash is shown in Table 3. 
Table 3 Fractional dimension of particle size distribution of fly ash

\begin{tabular}{cccc}
\hline Distribution & Fitting equation & $\begin{array}{c}\text { Correlation } \\
\text { coefficient }\end{array}$ & $\begin{array}{c}\text { Fractal } \\
\text { dimension }\end{array}$ \\
\hline S.Tsivilis distribution $(1)$ & $\mathrm{Y}=0.96427 \mathrm{X}+0.14552$ & 0.87209 & 2.03573 \\
S.Tsivilis distribution $(2)$ & $\mathrm{Y}=0.73242 \mathrm{X}+0.07737$ & 0.93522 & 2.26758 \\
Andersen distribution $(n=1 / 3)$ & $\mathrm{Y}=0.33433 \mathrm{X}-4.54381 \mathrm{E}-4$ & 0.99999 & 2.66567 \\
Andersen distribution $(n=0.37)$ & $\mathrm{Y}=0.81856 \mathrm{X}+0.07135$ & 0.96153 & 2.18144 \\
Normal distribution $(\mu=6.5)$ & $\mathrm{Y}=0.86735 \mathrm{X}+0.12099$ & 0.89638 & 2.13265 \\
Normal distribution $(\mu=12.5)$ & $\mathrm{Y}=1.72255 X+0.19966$ & 0.94909 & 1.27745 \\
\hline
\end{tabular}

As can be seen from the data in Table 3, the correlation coefficient of the fitted equation using linear regression analysis is between 0.87 to 0.99 . The fly ash of S.Tsivilis distribution, Andersen distribution and normal distribution has a good correlation. Thus, the obtained linearity of the fractal curve is better. At the same time, it shows that the distribution of fly ash has obvious fractal characteristics. Fractal dimension can be used as a quantitative characterization on the particle size distribution of fly ash.

Correlation between fractal dimension of particle size distribution and strength. The effect of different distributions of fly ash on the strength of the mortar was studied. The fractal dimension of fly ash and the flexural and compressive strength of mortar at $3 \mathrm{~d}, 7 \mathrm{~d}$ and $14 \mathrm{~d}$ are shown in Table 4 and Table 5, respectively.

Table 4 Fractal dimension of fly ash particle size distribution and flexural strength of mortar

\begin{tabular}{ccccc}
\hline Distribution & $\begin{array}{c}\text { Fractal } \\
\text { dimension }\end{array}$ & $\begin{array}{c}3 \mathrm{~d} / \\
\mathrm{Mpa}\end{array}$ & $\begin{array}{c}7 \mathrm{~d} / \\
\mathrm{Mpa}\end{array}$ & $\begin{array}{c}14 \mathrm{~d} / \\
\mathrm{Mpa}\end{array}$ \\
\hline Normal distribution $(\mu=12.5)$ & 1.27745 & 6.0 & 7.5 & 8.4 \\
S.Tsivilis distribution $(1)$ & 2.03573 & 5.5 & 6.7 & 7.9 \\
Normal distribution $(\mu=6.5)$ & 2.13265 & 5.3 & 6.8 & 7.5 \\
Andersen distribution $(n=0.37)$ & 2.18144 & 5.1 & 6.4 & 7.4 \\
S.Tsivilis distribution $(2)$ & 2.26758 & 5.2 & 6.6 & 7.6 \\
Andersen distribution $(n=1 / 3)$ & 2.66567 & 4.7 & 5.9 & 7.2 \\
\hline
\end{tabular}

Table 5 Fractal dimension of fly ash particle size distribution and compressive strength of mortar

\begin{tabular}{ccccc}
\hline Distribution & $\begin{array}{c}\text { Fractal } \\
\text { dimension }\end{array}$ & $\begin{array}{c}3 \mathrm{~d} / \\
\mathrm{Mpa}\end{array}$ & $\begin{array}{c}7 \mathrm{~d} / \\
\mathrm{Mpa}\end{array}$ & $\begin{array}{c}14 \mathrm{~d} / \\
\mathrm{Mpa}\end{array}$ \\
\hline Normal distribution $(\mu=12.5)$ & 1.27745 & 24.1 & 30.8 & 34.9 \\
S.Tsivilis distribution $(1)$ & 2.03573 & 20.9 & 29.3 & 33.2 \\
Normal distribution $(\mu=6.5)$ & 2.13265 & 21.3 & 28.5 & 32.2 \\
Andersen distribution $(n=0.37)$ & 2.18144 & 18.8 & 27.3 & 33.0 \\
S.Tsivilis distribution $(2)$ & 2.26758 & 19.0 & 26.2 & 32.6 \\
Andersen distribution $(n=1 / 3)$ & 2.66567 & 16.2 & 25.0 & 31.6 \\
\hline
\end{tabular}

For a more intuitive comparison, The relationship between the fractal dimension of the particle size distribution of fly ash and the flexural strength of mortar at $3 \mathrm{~d}, 7 \mathrm{~d}$ and $14 \mathrm{~d}$ is shown in Fig. 1 . The 
relationship between the fractal dimension of the particle size distribution of fly ash and the compressive strength of mortar 3d, 7d and 14d is shown in Fig 2.

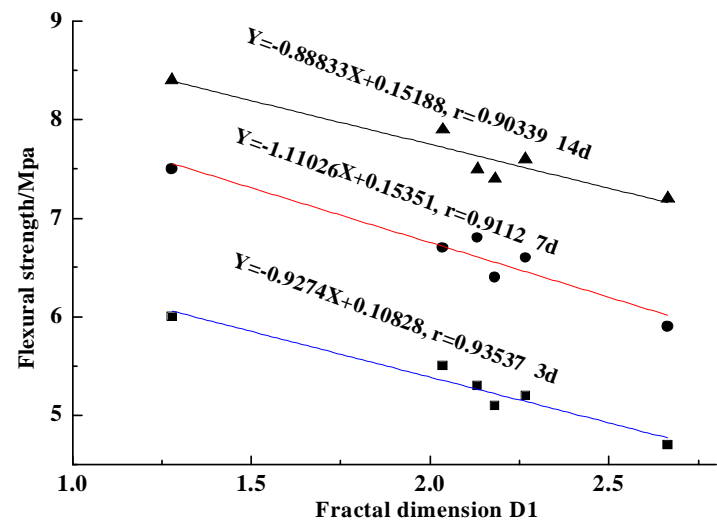

Fig.1 The relationship between the fractal dimension of the particle size distribution of fly ash and the flexural strength of mortar $3 \mathrm{~d}, 7 \mathrm{~d}$ and $14 \mathrm{~d}$

It can be seen from Fig. 1 that the fractal dimension of particle size distribution of fly ash is between 1.2 and 2.7, the correlation coefficient of linear regression analysis is greater than 0.9. It is shown that the fractal dimension of the particle size distribution of fly ash has a good correlation with the flexural strength of mortar 3d, $7 \mathrm{~d}$ and $14 \mathrm{~d}$. At the same time, with the increase of fractal dimension of particle size distribution of fly ash, the flexural strength values of cement mortar at $3 \mathrm{~d}, 7 \mathrm{~d}$ and $14 \mathrm{~d}$ are reduced to different degrees. When the fractal dimension increases 1.38822, the flexural strength of cement mortar $7 \mathrm{~d}$ decreases the fastest and decreases by $1.6 \mathrm{Mpa}$. Under the standard curing, the slope of the regression equation of cement mortar at $3 \mathrm{~d}$ and $7 \mathrm{~d}$ are lower than $14 \mathrm{~d}$, it is shown that the later strength of cement mortar increases with the increase of fractal dimension of fly ash. Among them, the compressive strength of cement mortar $7 \mathrm{~d}$ curve slope is the minimum, the increase of the later strength of mortar is more obvious and increase by $8.8 \mathrm{Mpa}$.

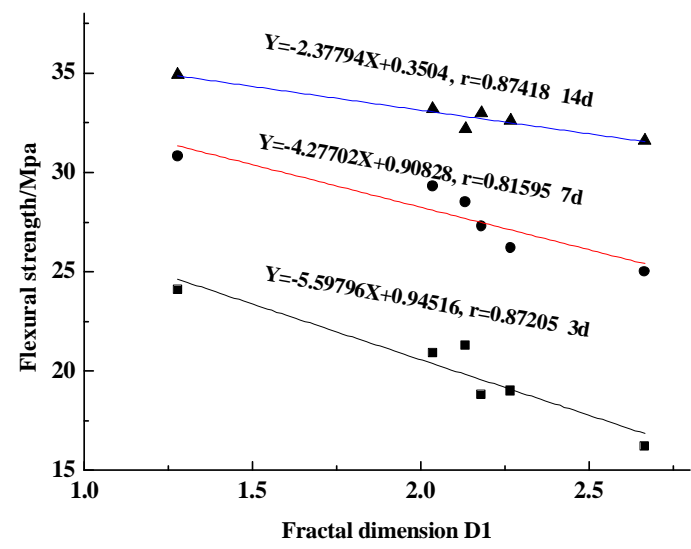

Fig.2 The relationship between the fractal dimension of the particle size distribution of fly ash and the compressive strength of mortar $3 \mathrm{~d}, 7 \mathrm{~d}$ and $14 \mathrm{~d}$

It can be seen from Fig. 2 that the fractal dimension of particle size distribution of fly ash is between 1.2 and 2.7, and the correlation coefficient of linear regression are greater than 0.8 , it is shown that the fractal dimension of the particle size distribution of fly ash has a good correlation with the compressive strength of mortar at $3 \mathrm{~d}, 7 \mathrm{~d}$ and $14 \mathrm{~d}$. At the same time, with the increase of fractal dimension of particle size distribution of fly ash, the compressive strength of cement mortar at $3 \mathrm{~d}, 7 \mathrm{~d}$ and $14 \mathrm{~d}$ are reduced to different degrees. When the fractal dimension increases 1.38822 , the compressive strength of cement 
mortar at $3 \mathrm{~d}$ decreases the fastest and decreases by 7.9Mpa. Under the standard curing period, the slope of the regression equation of cement mortar of $3 \mathrm{~d}$ and $7 \mathrm{~d}$ are lower than $14 \mathrm{~d}$, it is shown that the later compressive strength of mortar increases with the increase of fractal dimension of fly ash. Among them, slope of the compressive strength of cement mortar at $3 \mathrm{~d}$ is the minimum, the increase of later compressive strength of mortar is more obvious and increase by $15.4 \mathrm{Mpa}$.

\section{Conclusions}

Most of fractal dimension of Fly ash of S.Tsivilis distribution, Andersen distribution and normal distribution between 2.03573 to 2.66567 . Only fractal dimension of the normal distribution ( $\mu=12.5$ ) is 1.27745 , it shows that the particle size distribution of fly ash has obvious fractal characteristics, and the fractal dimension can be used as a quantitative characterization on the particle size distribution of fly ash.

The fractal dimension of particle size distribution of fly ash has a good correlation with the flexural and compressive strength values of mortar. At the same time, the correlation of mortar flexural strength is superior than the compressive strength.

With the increase of the fractal dimension of particle size distribution of the fly ash, the flexural and compressive strength values of the cement mortar at $3 \mathrm{~d}, 7 \mathrm{~d}$ and $14 \mathrm{~d}$ are reduced to different degrees.

With the increase of the fractal dimension of the fly ash, the later strength of the cement mortar is obviously increased. The correlation between the fractal dimension of the fly ash and the late strength of the cement mortar is greater than that of the early strength.

\section{Acknowledgements}

This work was financially supported by Shenyang Science and Technology Project 17-48-2-00.

\section{References}

[1] Liu Guan yu. Fly ash comprehensive utilization of the status quo and prospects [J]. Science and Technology Information Development and Economy, 2010,20 (19): 2-3.

[2] Zhang qinghuan. The mechanism of fly ash in the hydration process of composite cementitious materials [D]. Beijing: Qinghua University, 2006.

[3] Zhou Wanliang, Fang Kunhe, Zhan Binggen. Study on carbonation resistance of fly ash and fly ash concrete [J]. Journal of Concrete and Cement Products, 2012, (12): 1-3.

[4] WU Cheng-bao, DUAN Bai-tao. Study on fractal dimension evaluation of cement particle size distribution [J]. Cement, 2007 (5): 3-4.

[5] Duan Baitao, Wu Chengbao. Study on the relationship between the fractal dimension of cement particle size distribution and the compressive strength of mortar [J]. Cement, 2007 (10): 4-7.

[6] FENG Zhi-gang, ZHOU Hong-wei. Fractal dimension calculation method of image and its application [J]. Journal of Jiangsu University of Science and Technology (Natural Science Edition), 2001 (6): 5-8 